\title{
Women Professionals' in Automotive Industry through International College of Automotive (ICAM), Pekan, Malaysia.
}

\author{
Dr (Mrs) Muneer Sultana,Samsudin Shafii, Suhaidah Hussain \\ Department ofBusiness \&Management/International College of AutomotiveDRB.HICOM, Pekan, Malaysia
}

\begin{abstract}
This paper discusses about the Women Professionals in automotive industry through International College of Automotive. There are an incredible number of career choices for women in the automotive industry. Women are entering the field in record numbers and taking leadership roles in everything from manufacturing to design.Few women leading the pack and breaking down barriers in the auto world. As customers, women play a huge role in the field of automotive repair. Today, peek inside any major automaker window find not only female executives but also women designers, engineers, and technicians. The automotive industry wants girls! study aims to find out the knowledge of Girl's students in Automotive and the student's interest to do different types of job in different automotive industries. The study is prepared based on primary data as well as secondary data. The primary data has been collected from the different diploma programmes of Engineering \& Technology and Business \& Management departments of First, Second, Third, Fourth and Fifth Semesters Girl's students of ICAM by administering total Sample of 60 structured questionnaires. Ultimately, suggestions have been framedfor the improvement of girl's student in automotive career in ICAM.
\end{abstract}

Key Words: Women, Professionals, Automotive, International College of Automotive(ICAM).

Type: Research Paper.

\section{Introduction:}

Women have to play an important role in society, family and the country. They are made to fulfil the responsibilities as a daughter, sister, mother, wife and daughter-in-law in society and as a citizen of the country. Women are catalysts for change and when they are educated, empowered and healthy; they invest back into their families, communities and nations.

Many women are not aware of the opportunities available for them in the auto industry; the truth is thatthereis really no repair function that a woman can't perform. The possibilities are unlimited and a technical background can open up opportunities in the automotive industry that are hard to imagine. Thereis no denying that the automotive industry is male-dominated. But the industry is shifting gears. Women are entering the field in record numbers and taking leadership roles in everything from manufacturing to design. Few women leading the pack and breaking down barriers in the auto world. As customers, women play a huge role in the field of automotive repair. Women bring in up to two thirds of the vehicles brought to shops for maintenance and repair work. When it comes to automotive design, women have been instrumental and always played a leading role in the field of colour and trim.Not only women are gaining more power as automotive consumers, they are becoming more and more influential in developing what theconsumer'swould be buying.In the automotive industry, the inclusion of women is strongly encouraged and their number is slowly, but clearly, on the rise. Today, peek inside any major automaker window find not only female executives but also women designers, engineers, and technicians.

Auto Manufactures, service providers, independent repair shops and car dealerships want to hire more women in management positions, marketing, sales, service advisors, finance managers, parts departments and technicians. There are an incredible number of career choices for women in the automotive industry. A panel of automotive expert women review all the various roles which include race car drivers, automotive journalists to owners of automotive businesses. The automotive industry and specifically car dealerships, independent service and repair shops are looking to hire more women. There are many positions available to women in each and every department. Dealerships are high-tech facilities, with challenging and fast-paced work environments, requiring many skilled employees to keep the company running in an orderly fashion. Coming into an auto dealership from another career path can be an easy transition, since most jobs require a high level of interpersonal skills, as well as technical and computing skills. Not all jobs require any technical knowledge of automobiles, so there is truly an opportunity for anybody at a dealership. Many women are gravitating toward careers in the auto industry. Theautomotive industrywants girls!

Automotive Industry are all those companies and activities involved in the manufacture of motor vehicles, including most components, such as engines and bodies, but excluding tires, batteries, and fuel. The industry's principal products are passenger automobiles and light trucks, including pickups, vans, and sport 
utility vehicles. Commercial vehicles (i.e., delivery trucks and large transport trucks, often called semis), though important to the industry, are secondary.

The International College of Automotive (ICAM) is owned by HICOM University College SdnBhd (HUCSB), a wholly owned subsidiary of DRB-HICOMSdnBerhad. ICAM was officially established on the 2nd of April 2010, upon receiving approval from The Ministry of Higher Education, Malaysia.ICAM serves two major roles, acting as a private college that produces a cadre of skilled professionals to join the workforce for the automotive sector, and also serving as an institution that enables the Group's automotive workers to continuously upgrade their skills and knowledge. ICAM's goal is to complement the automotive industry through sustainable development of human capital. By providing a continuous flow of trained and skilled workers to the Group's automotive businesses, ICAM plays an active role in the Group's vision of realising the nation's aspiration of creating a knowledgeable and skilful workforce, as prescribed in the New Economic Model. This vision includes the goal of making Pekan, the home of ICAM and the Group's integrated automotive complex, a vibrant and self-sustaining regional automotive centre, which will house state-of-the-art technology but more importantly a highly skilled \& knowledgeable workforce . In ICAM nearly 200 Girl's students are pursuing different Diploma programmes under Engineering \& Technology and also under Business \& Management departments. The study has been conducted to know the knowledge of Girl's students in automotive when they are itself studying in automotive college and their interest to do different types of jobs in different automotive industries.

1.2. Need and Significance of the Study:Women play a significant role in the field of automotive repair. Women bring in up to two thirds of the vehicles brought to shops for maintenance and repair work. For the most part, the world of automotive careers remains dominated by men, but there are plenty of opportunities for women as well as reasons why the automotive field is a good place for women to be .To study the capacity building of Professionals in Automotive, there is great potential for the women to participate in Automotive Industry. In this context, there is a need of the study of women professionals in automotive industry.

\subsection{Objectives of the Study:}

1)To examine the knowledge ofGirl's students in automotive in ICAM.

2)To know the girls students interest to do different types of jobindifferentautomotive industries.

1.4. Period of the Study: period of the study isfor 2013 year.

1.5.Scope of the Study: The Study covers the knowledge of Girl's students in Automotive in International College of Automotive (ICAM), with special emphasis on interest of doing different types of jobs in different Automotive Industries.

1.6. Limitations of the Study:Only Girls Students of Diploma Programmes of International College of Automotive have been taken for the study, though a Boys students of Diploma Programmes of International College of Automotive are also studying in the college and as the study is based on the primary data, collected through Questionnaire method, the reliability depends on the true response of the Students of ICAM.

\section{Previous Studies.}

2.1. According to Women Institute of Management (WIM) 2011,indicated that they are helping women at all levelsand took its task of education a step further with the setting up of Education and Management Programmes in collaboration with the University of East London to have high quality of students like managing directors, CEOs, senior vice-presidents, general managers, and professionals in many industries. They are an asset of WIM, and an indication of WIM's ability to provide students with fantastic business networking opportunities.

2.2.The automotive industry's premier professional organizationsuch as"The Women's Automotive Association International",$(1995)^{2}$, recognizes the achievements of women in the industry; provide educational e-news to automotive career-focused individuals; build relationships through networking and other interactive forums; and encourage growth through mentoring, educational endeavours, and scholarships."

2.3. According to the opinion of The PRIME Minister Datuk Seri NajibRazak, $(2013)^{\mathbf{3}}$ in his opening address at the 23rd Global Summit of Women at Shangri-La called on the public and private sectors to intensify efforts to create conducive work environments to not only retain talent among women but also attract those who had left the workforce and challenged "the corporate sector to ensure women make up at least 30 per cent of senior decision-making positions and corporate boards, including in government-linked companies and various commissions, by 2016." 
2.4. Automotive Women's Alliance Foundation,(2011) ,stated that the increasing number of women in important roles is proof that things are happening organically to some degree. To use an example from the automotive industry, the BMW Group is strongly devoted to increasing diversity and ensuring equal opportunities in the company. The vehicle manufacturer feels that a diverse workforce will enable the company to remain highly efficient and effective, even when the employability of individuals changes as demographics and values shift. For example, concerning the integration of women, the BMW Group has set the promotion and recruitment of female employees and managers as a major objective. Activities range from promoting female students in technical vocational subjects and increasing the number of women in commercial-technical training to providing support for females in management positions.

2.5.Diversity and Equal Opportunities in Automotive Industry (2011) 5 has became a challenge for the automotive industry to create age-appropriate working conditions as the average age of the workforce rises. Meanwhile, as the existing workforce ages, securing the sufficient number of suitably skilled young people is proving a headache. The necessity to overcome the challenges of demographic change and skills shortage means diversifying the target workforce. Increasingly, and in line with companies' Corporate Social Responsibility (CSR) aims, companies are making sure to widen the scope and inclusiveness of their teams. This means including a wide range of different nationalities and ethnicities, as well as different age groups and increasing the share of women in the automotive workforce.

2.6. Women in Automotive (WinA) (1999) ${ }^{6}$,network is an initiative by women for women who work or operate businesses in the automotive industry. It was established with the primary purpose of:

- raising the profile of women and recognise their vital contribution to the automotive industry

- providing networking and mentoring opportunities for women within the industry and

- Enhancing the image of women in the industry.

2.7. According toMarina Shoemaker $(2011)^{7}$,opined that thethe General Motors Women's Retail Network the first automaker in the industry is to establish a program to actively recruit women into the automotive retail field as part of efforts to increase the number of women dealers in network and is launching a scholarship program to encourage women to consider a career in automotive retail.

2.8. Women in the Automotive Industry $(2009)^{8}$ indicated that as acustomers, women play a huge role in the field of automotive repair. Comprising a little more than half the US population, women bring in up to two thirds of the vehicles brought to shops for maintenance and repair work. When think about it, women have been hugely responsible for making the industry what it is today.

2.9. Chevrolet Preview ( 1990$)^{9}$, had believed that both women and black employees have precisely the abilities in automotive industries need to improve customer satisfaction, sales, and overall performance .Currently, federal laws mandate the employment of women and minorities in non-traditional fields such as automotive service. Diverseenrolments hopefully will enhance the opportunities of all the students to achieve their career goals, fulfil corporate needs, and be satisfied members of society.

2.10. According toLyndaAttack $(2011)^{10}$,opined that a career in the skilled trades offers women many benefits, yet efforts to recruit women into this career path have had limited success. A longitudinal study was conducted to explore students' experiences with a women-cantered Automotive Service Training pre-apprenticeship program that included innovations designed to support women entering this skilled trade. The women-only program provided a gender-sensitive classroom environment, and holistic program content to meet the needs of women holding multiple roles, as well as social and personal supports in the form of coaching, mentoring and advocacy.

\section{Research Methodology:}

3.1. Sources of Data: - the study is prepared based on primary data as well as secondary data. The primary data has been collected from the different diploma programmes of Engineering \& Technology and Business \& Management departments of First, Second, Third, Fourth and Fifth Semesters Girl's students of ICAM by administering total Sample of 60 structured questionnaires. The questionnaire covers the knowledge of Girl's students in Automotive and the student's interest to do different types of job in different automotive industries. The Secondary data has been collected from the records of the Students affairs department of ICAM and all possible existing literature is obtained by covering journals, books, online magazines, and publications. 
Analysis of Data: Tables have been prepared to show the presence or absence of specific characteristics and to compare and contrast data values or characteristics among related items with several shared characteristics or variables.

IV. Results and Discussion:

Table.4.1:-Knowledge of Automotive after studying in ICAM.

\begin{tabular}{|c|c|c|c|c|}
\hline \multirow{3}{*}{$\begin{array}{l}\text { Knowledge } \\
\text { Automotive }\end{array}$} & \multicolumn{3}{|c|}{ Girl's Respondents } & \multirow[t]{3}{*}{ Total } \\
\hline & \multicolumn{2}{|c|}{ Engineering \& Technology } & Business \& Management & \\
\hline & \begin{tabular}{|lll} 
DMS & DVA & DVI \\
\end{tabular} & DST & DRM DPV DRP DPM & \\
\hline Yes & 06 & 06 & 09 & 55 \\
\hline No & - & - & 02 & 05 \\
\hline Total & $06 \quad 06$ & 06 & $11 \quad 09$ & 60 \\
\hline
\end{tabular}

Source: Primary Data.

Table .4.1.Shows about the total number of Girlstudent's Knowledge of automotive after studying in International College of Automotive (ICAM). Under Business \& Management, Out of total sample of 60 girls students, 10 students from DPM followed by nine and eight each girls of respective programmes of DPV, DRP and DRM have responded positively towards knowledge of automotive after studying in ICAM. Only two each and one girl of DRM, DPV and DRPprogrammes of ICAM responded negatively towards knowledge of automotive.

Under Engineering \& Technology, Out of total sample of 60 girls students, six each and two girls respondents of DMS,DVA,DST and DVI programmes have responded positively towards knowledge of automotive after studying in ICAM respectively.

Therefore, it can be concluded that the maximum girl's respondents have knowledge of automotive after studying in ICAM, because it is compulsory when they are itself studying in automotive college.
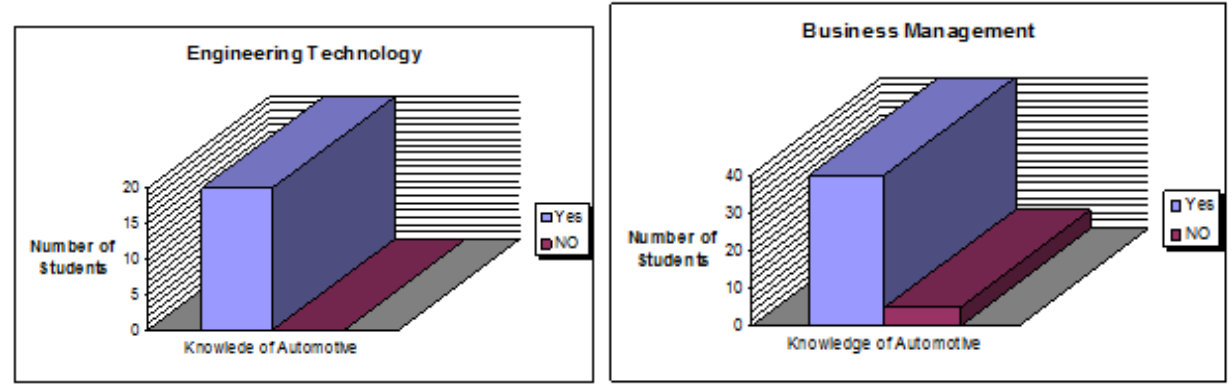

Table.4.2:- Students intention to do different types of Job in Automotive Industry.

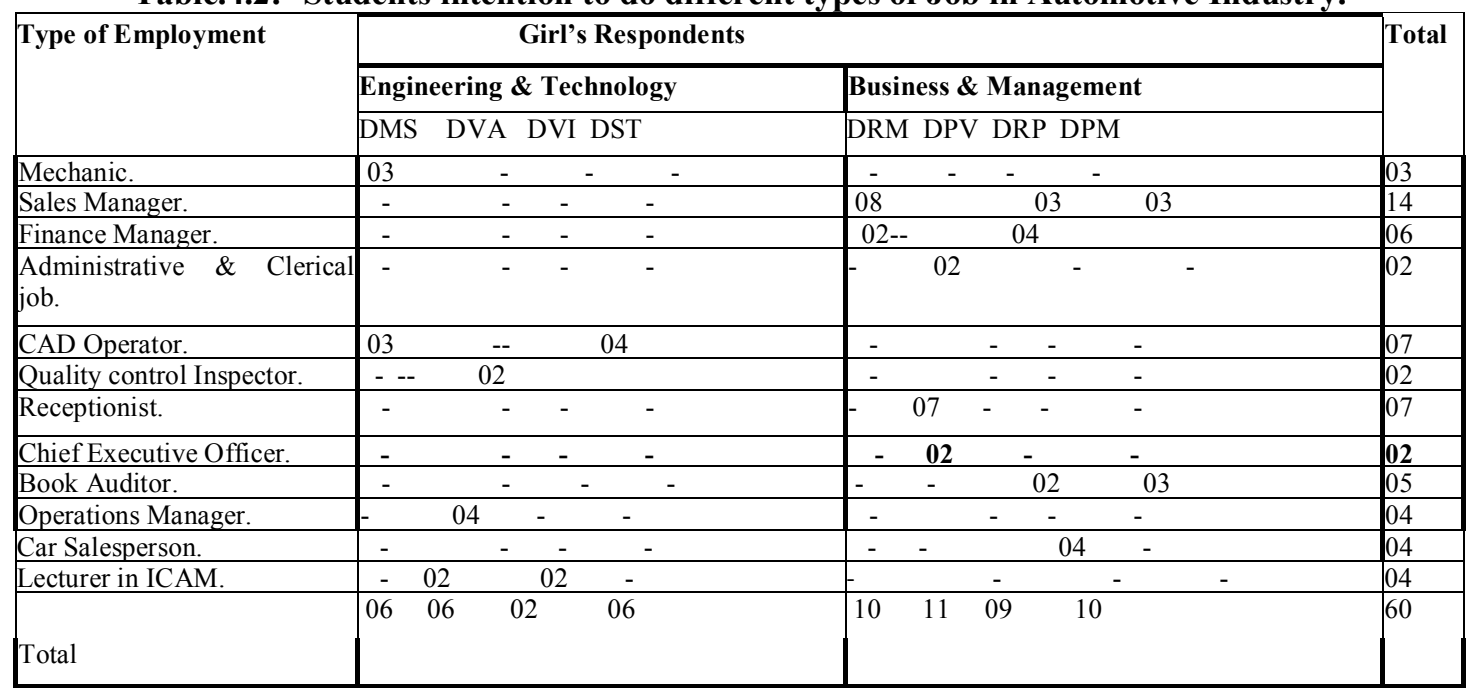

Source: Primary Data. 


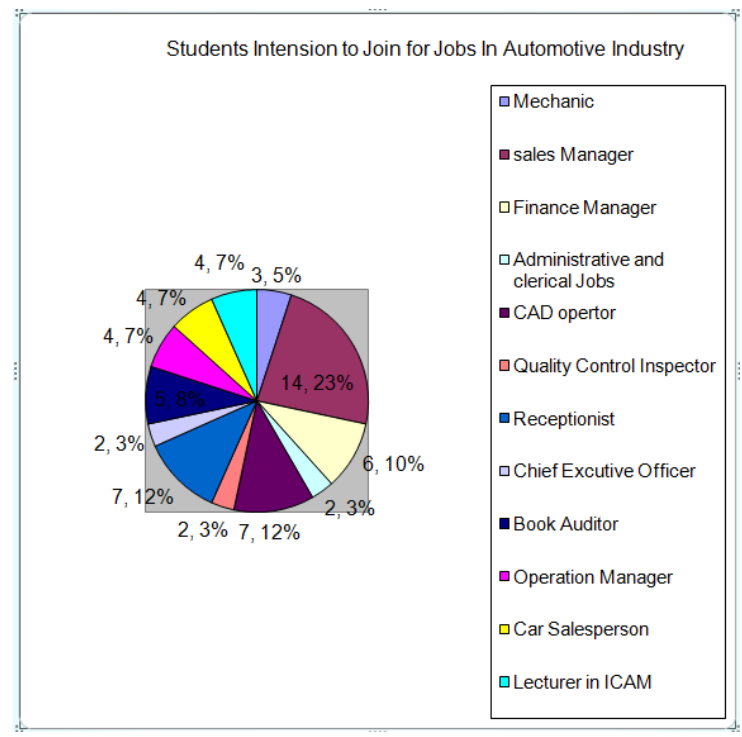

Table .4.2.depicts about the total number of Girl student's interest to do different types of job in automotive industry. Under Business \& Management, Out of total sample of 60 girls students, eight girl's respondents of DRM programme have interested to do job as Sales Manager, followed by seven girl's student, four each, three each and two each girl's respondent of DPV, DRP, DPM and DRM programmes have interested to do job as Receptionist, Car Sales Person, Finance Manager, Sales Manager, Book Auditor, Chief Executive Officer, Administrative and Clerical job respectively.

Under Engineering \& Technology, Out of total sample of 60 girl'sstudents, four each respondents of DST and DVA programme want to do job as Computer Aided Design (CAD) operator and Operation Manager respectively. Three each and two each girl's respondent of respective programmes of DMS, DST, DVA and DVI has interested to do job as Mechanic, CAD operator, Quality Control Inspector and Lecturer in ICAM respectively.

Therefore, it can be concluded that the maximum girl's respondents have interested to do under Management and Administrative positions, because of heavy weight and hard vehicle work they do not want to work in machinery. Only few girls' student wants to join in Manufacturing and Mechanic work in automotive industry, because they want to be equal with men in work in automotive industry.

SUGGESTIONS:the following are the suggestions for the improvement of girl's student in automotive career. 1). Finding out the research reveals that the majority of the girl's student have knowledge of automotive and they have interested to do job in administration and management positions rather than manufacturing and mechanic jobs in automotive industry, in such acase, while marketing all the automotive programmes, especially for the girl's, the management of ICAM should promoteit as an automotive college open to all customers, job seekers, regardless of gender.

2). ICAM management should provide a Girl's forum to enhance skills and education by encouraging them to increase knowledge in automotive of manufacturing and mechanic field.

3). Ultimately, a Scholarship Programme in Automotive Technology should be launch to encourage girl's students to consider career in automotive field.

\section{Conclusion:}

Therefore, it iswell-known fact that women influence the majority of automotive purchasing decisions, which is creating more career opportunities for women in automotive retailing and accommodating women who want to balance work and family responsibilities. There are more female auto technicians in the field than an an time in history. Truth is, there will always be an open number of employment slots that will be available for both men and women to fill. As long as there are vehicles on the road, there will be a need for qualified technicians. There's no denying that the automotive industry is male-dominated. But the industry is shifting gears. Women are entering the field in record numbers and taking leadership roles in everything from manufacturing to design. Women leading the pack and breaking down barriers in the auto world., it certainly has been getting more and more cracks as an increasing number of women have been achieving top level positions in many areas such as automotive journalists, owners, and industry executives. Working in the automotive industry can be extremely challenging task, especially because so many people have negative perceptions and 
opinions about the industry because women educates the customers, helping them to change their perception or attitude about auto repair.

\section{References:-}

[1]. "Women Institute of Management" available at: http//www.wimnet.org.my

[2]. "women's Automotive Association International"

[3]. Available at:http//www.waai.com

[4]. PRIME Minister Datuk Seri NajibRazak (2013),23rd Global Summit of Women at Shangri-La, New Straits Times07 June 2013.

[5]. "Automotive Women's Alliance Foundation" available at

[6]. http//“"www.awafoundation.org.

[7]. "About Our Future Mobility Now" available at:h// "www.futuremobilitynow.com

[8]. "Victorian Automotive Chamber of Commerce" available at $: \mathrm{h} / \mathrm{hwww.vacc.com.au}$

[9]. "Chronicle Online (2011)" available at :h//www.chronicletelegram/info

[10]. "Women in Automotive Careers "available at :h//www.careerealism.com/careers-automotive-women

[11]. Chevrolet Preview Educational Guide. (1990). Why women mean business. [Brochure].

[12]. Lynda Atack (2011), "Students' Experiences of aWomen-Only Automotive Service Technician Pre-apprenticeship Program", The Canadian Journal of Career Development, Volume 10, Number 1, 2011. 